\title{
Trends in Productive Years of Life Lost to Premature Mortality Due to Coronary Heart Disease
}

\author{
Ines Lessa
}

Salvador, BA - Brazil

\begin{abstract}
Objective - To estimate the number of productive years of life lost to premature death due to coronary heart disease in Brazil and to report their trends over a 20-year period.
\end{abstract}

Methods - The Brazilian Ministry of Health raw database on death due to coronary heart disease from 1979-1998 was used. The productive years of life lost to premature death were estimated using 20 and 59 years of age as the cut points for the productive years, replacing the potential years of 1 and 70 of the original formula. A descriptive analysis was provided with adjustments, means, proportions, ratios, percentages of increase or reduction, and mobile means.

Results - A 35.8\% increase in death for males and $51.3 \%$ for females was observed, $+43.3 \%$ being the relative difference for females. The annual means of the productive years of life prematurely lost were analyzed in 140,865 males and 58,559 females, with the differential ratio between the age groups ranging from 2.3 to 2.5. The annual means were less favorable for males. Within each group (intragroup), the ratios decreased with the increase in age, and the age means at the time of death remained constant. The raw tendencies decreased in the 20-to 29-year age group and increased in the 40-to 59-year age group for females and the 40- to 49-year age group for males. When adjusted, the raw tendencies decreased.

Conclusion - The 43.3\% increase in the number offemale deaths as compared with that of males and the ascending tendency in the productive years of life lost in the 40to 59-year age group point to the influence of unfavorable changes in female lifestyles and suggest a deficiency in programs for prevention and control of risk factors and in their treatment in both sexes.

Keywords: coronary heart disease, premature mortality, productive years of life, age

Instituto de Saúde Coletiva da Universidade Federal da Bahia

Mailing address: Ines Lessa - Rua Barachísio Lisboa, 3 - Parque Lucaia - 40295 120 - Salvador, BA, Brazil - E-mail: ines@ufba.br

English version by Stela Maris C. e Gandour
Excluding the magnitude of coronary heart disease and the direct costs of its in-hospital treatment, the social impact on the productive years of life is not well known even in developed western countries. Well-known studies about this issue are related to years of potential life lost, with low and high age cut points of 1 and 70 years ${ }^{1,2}$, respectively, which are different from the ages considered economically productive.

In countries that have not consolidated the epidemiological transition, as in $\mathrm{Brazil}^{3}$, with little investment in the prevention of nontransmissible chronic diseases, cardiovascular diseases occur early and account for elevated costs to society ${ }^{4,5}$. The treatment of risk factors, such as diseases (hypertension, diabetes, obesity, and hyperlipemia), is unequal among social classes, the compliance to treatment is low, and, consequently, control is inadequate ${ }^{6-8}$. In the case of coronary heart disease, the most advanced investigative and therapeutic technologies used in cardiovascular emergencies have not homogeneously reached the different social classes. When the population assisted by the public health system (Sistema Único de Saúde) has access to cardiovascular procedures, implementation of procedures rarely occurs with the speed necessary for the best prognosis (Emergências Cardiovasculares em Salvador, Lessa, personal communication), resulting in deaths that could be avoided, particularly during the productive years.

The lack of official and comprehensive information about this issue, particularly regarding morbidity and retirement due to disability/invalidism consequent to premature coronary heart disease, impairs the global measurement of the social impact of the disease. That is why studies based on death are the most feasible and nondiscriminatory, because of the inclusion of all deaths, of all social classes, and of all assisting resources.

Knowing about the productive years of life lost to premature death provides important information to the health sector and social security. It partially reflects the social impact of the diseases, whose prevention or control, or both, are unquestionably beneficial. The results of some 
national studies on all cardiovascular diseases, particularly cerebrovascular diseases ${ }^{5,9}$, and on noncardiovascular diseases ${ }^{10,11}$ were published in the 1990s. When these results are used rationally, they may guide more consistent decisions about preventive and control strategies or uninterrupted actions, or both, for cardiovascular diseases in general.

The present study aimed at estimating the number of productive years of life lost to premature death due to coronary heart disease in Brazil and at reporting their tendency in a 20 -year period.

\section{Methods}

This is a tendency study over time (1979/1998) of the productive years of life lost to death due to coronary heart disease during economically active years. The Brazilian raw database was directly obtained from the information system on mortality (Sistema de Informação de Mortalidade - SIM) of the Centro Nacional de Epidemiologia of the Fundação Nacional de Saúde of the Brazilian Ministry of Health (www.datasus.gov.br) for the 20- to 59-year age group and for both sexes. The deaths were recorded in the official statistics as "ischemic heart disease" and were grouped under the numbers 410 to 414 of the International Classification of Diseases and Causes of Death, 9threview for the 1979-1995 period, and as the same causes in an alphanumeric code in the 10th review for the years 1996 to 1998 . The population figures for the years 1980 and 1998 were obtained in the IBGE (Brazilian Institute of Geography and Statistics) only for calculating the mortality rates due to coronary heart disease in 2 temporal points (1980 and 1998).

The productive years of life lost were calculated according to the formula of Roemeder and McWhinnie ${ }^{1}$, previously modified by Lessa and already used in other publications $^{5,10,11}$. The modification consisted of replacing the original cut points for calculating the potential years of life lost by 20 (lower cut) and 60 years (higher cut), considering this the predominant age group of the economically active life and a parameter for calculating the productive years of life lost, as follows: productive years of life lost $=\Sigma f(60-(\mathrm{X}$ $+0.5)$ ), where $f=$ frequency of death for each age group; $60=$ higher cut point of age, $\mathrm{X}=$ mean point of the class interval of the age brackets; and 0.5 = factor of correction (appendixes I and II).

The analysis was descriptive with raw frequencies of the productive years of life lost adjusted for age and sex, with an adjusting parameter of the deaths that occurred during 1980 in Brazil at the same ages and from the same causes. To construct the pictures, we used the mobile means, order 3, of the frequencies of the productive years of life lost in all years of the series. Means, standard deviations, and intergroup (male $\mathrm{x}$ female) and intragroup (age brackets) mean ratios were calculated for the productive years of life lost, as were the percentages of increase or re- duction in the number of deaths in the period and the increase/reduction ratios. The test of difference between 2 proportions was used in some analyses.

\section{Results}

During the 20 years studied, the annual deaths due to coronary heart disease in males ranged from 10,747 to 14,591 , and the number of productive years of life lost ranged from 119,165 to 157,805. During the same period of time, the annual deaths due to coronary heart disease in females ranged from 4,272 to 6,465 , and the number of productive years of life lost ranged from 47,470(1982) to 68,625 (appendixes I and II).

Table I shows the percentages of increase or reduction in the number of deaths due to coronary heart disease. A $51.3 \%$ increase was observed for females and a $35.8 \%$ increase for males (fig. 1) with unfavorable absolute and relative differences in the female sex of $+15.5 \%$ and $+43.3 \%$, respectively. The dynamics of the increases and reductions in deaths is shown with 3 different approaches in columns A, B, and C of table I: A) of each age group in regard to the one that is immediately below it, in which the 30-39 group stands out in regard to the 20-29 group for males, and the 4049 group in regard to the 30-39 group for females; B) of the highest age group in regard to lowest ones. Lower ratios are observed for males; $C$ ) of each age group in regard to the youngest of all (20-29 years), with very high values for females, and a special emphasis for the 40- to 49-year age group with a 16.8-times greater ratio.

Table II shows the annual means and the mean ratios of the productive years of life lost to premature deaths. For males, the annual mean loss was 140,865 productive years, 2.4 times greater than that for females, for whom the annual mean loss was 58,559 productive years. In all age brackets, the losses in the male sex were 2.3 to 2.5 times greater than those in the female sex. Considering the intragroup perspective, the mean ratios were practically the same for males and females, when each age group was compared to the immediately lower one (column A), and they did not differ between the sexes when the 50- to 59-year age group was compared with all others (column B).

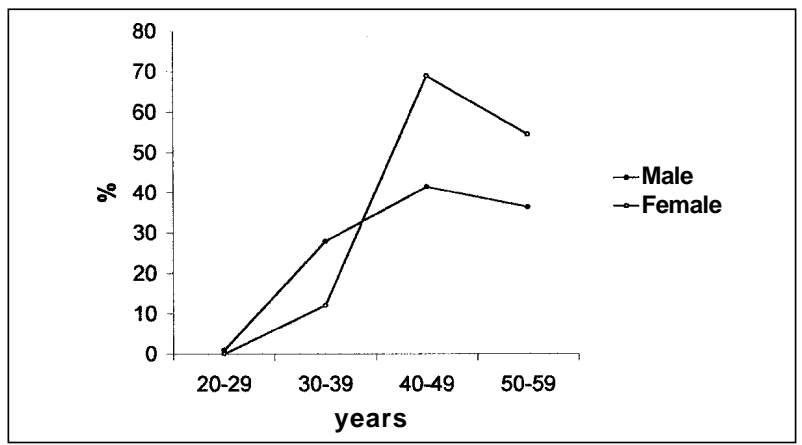

Fig. 1 - Frequencies of increase or reduction in the number of deaths due to coronary heart disease in Brazil from 1979 to 1998. 
During the 20 years studied, no significant alteration was detected in the mean ages of males and females at the time of death in the 20- to 59-year age group. The means ranged from 48.3(1989) to 48.8(1982) years for the males (maximum difference of 0.5 years, and mode $=48.6$ years $)$ and from 48.2(1979) to 49.1 (1992) years for the females (maximum difference of 0.9 years, and nonsignificant mode) (tab. III).

The population and the number of deaths observed in isolation increased more for females from 1980 to 1998 $(\mathrm{p}<0.0001)$, but the population increase in the male sex as compared with the increase in the number of deaths $(+41.6 \%)$ was $84 \%$ greater than the increase observed for females $(+22.6 \%)$ (tab. IV). The ratios between the mortality rates for males and females, 2.6 (1980) and 2.5 (1998), did not change over time, but a more significant reduction was observed in the male rates, whose drop was $52.3 \%$ as compared with that of the female sex.

The mobile means of the raw (fig. 2) and adjusted (fig. 3) frequencies of the productive years of life lost showed slightly decreasing tendencies for the 20 - to 39 -year age group; for the 40-49-year age group, the frequencies were similar between the sexes and the curves were ascending. A slightly ascending tendency was observed in the 50- to 59-year age group, more evident in females. When adjusted (fig. 3), all curves were descending.

\section{Discussion}

In the 20 years studied, the increase in the number of deaths due to coronary heart disease during economically

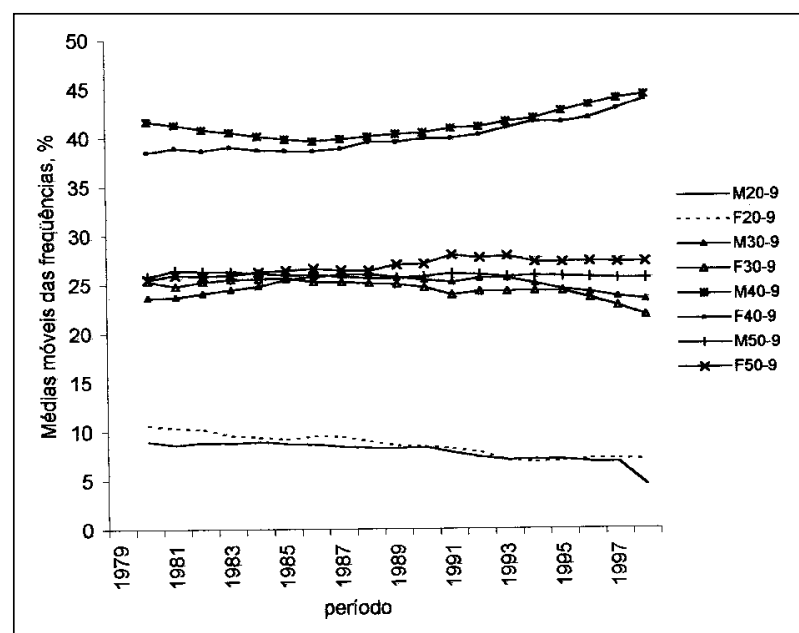

Fig. 2 - Tendency of the raw frequencies of the productive years of life lost to coronary heart disease in both sexes in Brazil from 1979 to 1998.

productive years for both sexes was significant, although more expressive in females. This increase does not necessarily mean that the probability of dying due to the above-specified cause has increased homogeneously, because the basis for calculation was the number of deaths due to coronary heart disease in the country and not the population. In addition, some authors have reported that mortality due to coronary heart disease has been slowly decreasing with no explanation in the municipality of São Paulo and in some age brackets in some selected capitals ${ }^{12,13}$. In the age groups and period of time studied, a small reduction

\begin{tabular}{|c|c|c|c|c|c|c|c|c|c|c|}
\hline \multirow[t]{2}{*}{ Age } & \multirow{2}{*}{$\begin{array}{l}\text { Male } \\
\% \text { of increase } \\
\text { or reduction }\end{array}$} & \multicolumn{3}{|c|}{$\begin{array}{c}\text { Intragroup ratio } \\
\text { of increase }\end{array}$} & \multirow{2}{*}{$\begin{array}{c}\text { Female } \\
\% \text { of increase } \\
\text { or reduction }\end{array}$} & \multicolumn{3}{|c|}{$\begin{array}{c}\text { Intragroup } \\
\text { ratio of increase }\end{array}$} & \multirow{2}{*}{$\begin{array}{c}\text { Absolute } \\
\text { difference of the } \\
\text { F/M } \%\end{array}$} & \multirow{2}{*}{$\begin{array}{c}\text { Relative difference } \\
\text { Fem/Male } \% \text { of } \\
\text { increase or reduction }\end{array}$} \\
\hline & & $\mathrm{A}^{*}$ & $\mathrm{~B}^{* *}$ & $\mathrm{C}^{* * *}$ & & $A^{*}$ & $\mathrm{~B} * *$ & $\mathrm{C}^{* * *}$ & & \\
\hline $20-29$ & -6.6 & - & 5.5 & - & -4.1 & - & 13.3 & - & -2.5 & -61.0 \\
\hline $30-39$ & +27.9 & 4.2 & 1.3 & 4.2 & +12.1 & 3.0 & 4.5 & 3.0 & -15.8 & -130.6 \\
\hline $40-49$ & +41.4 & 1.5 & 0.9 & 6.2 & +68.9 & 5.7 & 0.8 & 16.8 & +27.5 & +66.4 \\
\hline $50-59$ & +36.4 & 0.9 & - & 5.5 & +54.4 & 0.8 & - & 13.3 & +18.0 & +49.5 \\
\hline Total & +35.8 & & & & +51.3 & & & & +15.5 & +43.3 \\
\hline
\end{tabular}

\begin{tabular}{|c|c|c|c|c|c|c|c|c|c|}
\hline \multirow{2}{*}{ Ages } & \multicolumn{4}{|c|}{ Male } & \multicolumn{4}{|c|}{ Female } & \multirow{2}{*}{$\begin{array}{c}\text { Male/fem } \\
\text { intergroup MR }\end{array}$} \\
\hline & Mean & $\pm \mathrm{SD}$ & $\mathrm{A}^{*}$ & $\mathrm{~B}^{* *}$ & Mean & $\pm \mathrm{SD}$ & $\mathrm{A}^{*}$ & $\mathrm{~B}^{* *}$ & \\
\hline $20-29$ & 11.196 & 1.054 & - & 3.2 & 4.950 & 563 & - & 3.1 & 2.3 \\
\hline $30-39$ & 35.525 & 3.486 & 3.2 & 1.0 & 14.388 & 1.378 & 2.9 & 1.1 & 2.5 \\
\hline $40-49$ & 58.248 & 5.431 & 1.6 & 0.6 & 23.540 & 3.340 & 2.4 & 0.7 & 2.5 \\
\hline $50-59$ & 36.444 & 2.672 & 0.6 & - & 15.581 & 1.939 & 0.7 & - & 2.3 \\
\hline Total & 140.865 & 2.672 & & & 58.559 & 6.291 & & & 2.4 \\
\hline
\end{tabular}




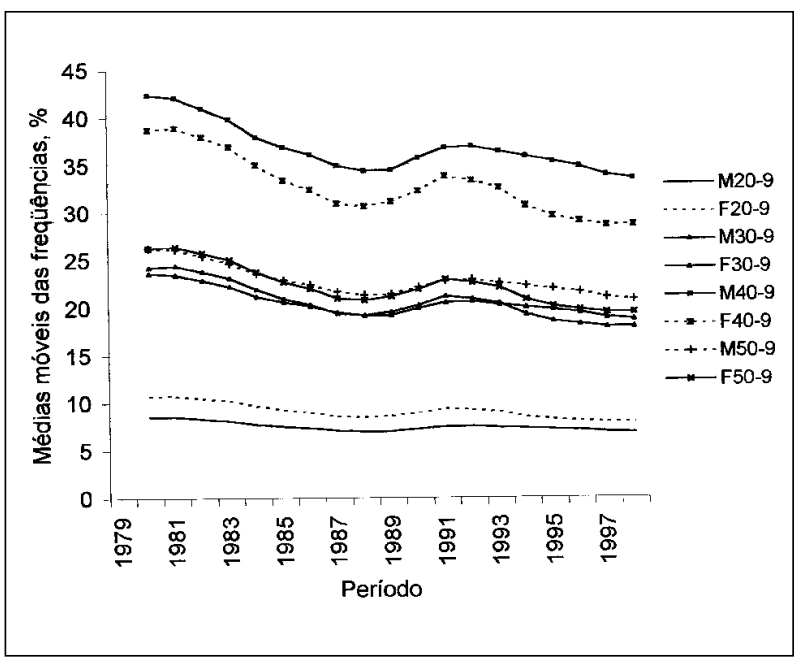

Fig. 3 - Tendency of the adjusted frequencies of the productive years of life lost to coronary heart disease in both sexes in Brazil from 1979 to 1998.

in the mortality rates for each sex was observed, with a significant gain of $52.3 \%$ for males as compared with that for females. In other countries, an increase in mortality due to coronary heart disease has been recently seen in young black males from the lower social class ${ }^{2,14-16}$.

When comparing the dynamics of the population with that of the deaths, the greater population increase observed in females did not benefit them as occurred with that observed in males, whose percentage increase in population in regard to deaths was $84 \%$ greater than that in the females.

In the sparse international literature about the productive years of life lost, information has been usually related to heterogeneous sets of causes of death ${ }^{2,17,18}$ and has originated in countries with greater life expectancy than that in Brazil, with no possibility of comparison with the national data. Premature deaths due to certain causes occurring between 20 and 64 years of age in different social classes and in the male sex have been analyzed only in England; unfavorable and growing differences were found for the cardiovascular diseases in the lower social class ${ }^{2}$.

Although in the national data, the greatest number of deaths and of productive years of life prematurely lost to coronary heart disease was observed in the male sex, the percentage increase was more significant in females, especially

\begin{tabular}{|c|c|c|c|c|}
\hline \multicolumn{5}{|c|}{$\begin{array}{l}\text { Table III - Mean and standard deviation (SD) of age at the time of } \\
\text { death due to coronary heart disease in the 20- to 59-year age group for } \\
\text { both sexes in Brazil, 1979-1998 }\end{array}$} \\
\hline \multirow[b]{2}{*}{ Year } & \multicolumn{2}{|c|}{ Male } & \multicolumn{2}{|c|}{ Female } \\
\hline & Mean & SD & Mean & SD \\
\hline 1979 & 48.4 & 7.9 & 48.2 & 8.3 \\
\hline 1980 & 48.6 & 7.8 & 48.5 & 8.1 \\
\hline 1981 & 48.6 & 7.8 & 48.4 & 8.1 \\
\hline 1982 & 48.8 & 7.8 & 48.5 & 8.0 \\
\hline 1983 & 48.5 & 7.9 & 48.4 & 8.2 \\
\hline 1984 & 48.6 & 7.9 & 48.5 & 7.9 \\
\hline 1985 & 48.6 & 7.9 & 48.7 & 8.0 \\
\hline 1986 & 48.4 & 7.9 & 48.5 & 8.1 \\
\hline 1987 & 48.6 & 7.9 & 48.6 & 7.9 \\
\hline 1988 & 48.5 & 7.9 & 48.6 & 8.0 \\
\hline 1989 & 48.3 & 7.9 & 48.6 & 7.9 \\
\hline 1990 & 48.6 & 7.8 & 48.9 & 7.7 \\
\hline 1991 & 48.6 & 7.8 & 48.7 & 7.9 \\
\hline 1992 & 48.6 & 7.7 & 49.1 & 7.6 \\
\hline 1993 & 48.6 & 7.7 & 48.8 & 7.6 \\
\hline 1994 & 48.6 & 7.7 & 48.9 & 7.5 \\
\hline 1995 & 48.7 & 7.6 & 48.9 & 7.6 \\
\hline 1996 & 48.6 & 7.6 & 48.8 & 7.7 \\
\hline 1997 & 48.6 & 7.6 & 49.0 & 7.5 \\
\hline 1998 & 48.7 & 7.5 & 48.9 & 7.5 \\
\hline
\end{tabular}

in the 40- to 49-year age group. This suggests that the load of risk factors (smoking, obesity, arterial hypertension, hyperlipemia, diabetes, sedentary lifestyle, and stress), infrequent among Brazilian females prior to the last 3 or 4 decades, has been prematurely acquired and is expressed in this age group as significant morbidities, such as coronary heart disease.

Although it is very likely that this hypothesis is true, as is evident by the dynamics of the data shown in table IV, the lack of complementary Brazilian temporal series, of not only social variables but also the prevalence of risk or prognostic factors, restricts explanations about the tendencies at the present moment. The curves based on raw data show that the growing tendency was maintained in the 40 - to 49year age group in both sexes. This is reflected in the magnitude of the productive years of life lost and in the stability of the mean age at the time of death, represented by a plateau slightly above 48 years, independent of sex, and during the entire period studied. This may also be observed by the magnitudes of the increasing ratios of the proportions of intragroup deaths in the 40- to 49-year age group as compared

\begin{tabular}{|c|c|c|c|c|c|c|c|c|c|c|}
\hline \multirow[b]{2}{*}{ Sex } & \multicolumn{3}{|c|}{ Population } & \multicolumn{3}{|c|}{ Deaths } & \multirow[b]{2}{*}{$\begin{array}{l}\% \text { of increase of } \\
\text { the population in } \\
\text { regard to deaths }\end{array}$} & \multicolumn{3}{|c|}{ Mortality rate** } \\
\hline & 1980 & 1998 & $\begin{array}{c}\% \text { of } \\
\text { increase }\end{array}$ & 1980 & 1998 & $\begin{array}{c}\% \text { of } \\
\text { increase }\end{array}$ & & 1980 & 1998 & $\%$ of reduction \\
\hline Male & $26,088,125$ & $39,309,214$ & 50.7 & 11,371 & 15,445 & 35.8 & +41.6 & 43.6 & 39.3 & -9.9 \\
\hline Female & $26,088,125$ & $41,113,449$ & 53.8 & 4,492 & 6,465 & 43.9 & +22.6 & 16.8 & 15.1 & -6.5 \\
\hline \multicolumn{11}{|c|}{$\begin{array}{l}\% \text { of differences or ratios, } \\
\text { R,between the sexes }\end{array}$} \\
\hline
\end{tabular}


with the youngest one used as a baseline (columns of tab. I). Considering the accelerated aging of the Brazilian population, a greater concentration of the frequency of death and of the productive years of life lost should be expected in the 50 - to 59-year age group. A mean age at the time of death shifting to the lower ages of this age group should also be expected, that is, the migration of deaths to more advanced ages. However, the ratio of the 50- to 59-year age group in regard to the 40 - to 49 -year group was lower than the unit, because the increase in deaths in the latter group was greater. Premature deaths in both sexes occurred approximately 11.5 years before age 60 , around which time retirement occurred, until the last year of the series, 1998.

In some countries, such as in the United States of America, the financial impact of coronary heart disease in premature ages is also significant; 10 years ago, only in California, the costs reached 5,200 billion dollars ${ }^{19}$. This information shows the socioeconomic burden of coronary heart disease in only 1 state of a wealthy country. In the 1980s, the costs of cerebrovascular diseases in Brazil were partially estimated ${ }^{5}$. They have been difficult to determine from that point on because of the economic instability and changes in the Brazilian currency in the last 2 decades, requiring correction of the values and exchange into a stable currency, usually the North American dollar.
The $50 \%$ and $57 \%$ drops in mortality due to coronary heart and cerebrovascular diseases, respectively, reported in the United States in 1997, with no reference to age, have been mostly attributed to the treatment of arterial hypertension ${ }^{20}$. In Auckland, New Zealand, half of the $23.6 \%$ drop in mortality due to coronary heart disease (1982/1993), with no reference to age, has been attributed to treatment, and the other half to preventive measures ${ }^{21}$. Both studies show how and how much mortality due to coronary heart disease can be reduced. Naturally, these reductions should reflect favorably in the costs and in other social impacts of the disease.

The analysis of the productive years of life lost to premature mortality due to coronary heart disease may, on the one hand, represent 1 of the feasible parameters to monitor that disease in Brazil, and, on the other, a landmark to further analyses of the impact of preventive strategies on risk factors, mainly smoking, obesity, and hypertension, which also contribute to several other causes of death. It is worth noting, however, that distortions in the analyses of historical series in Brazil may be due to the diagnoses reported on the death certificates as the basic cause of death by the assisting physician or the one responsible for filling out the certificate, or to the errors of selecting the basic cause of death, or to its typing, this latter in a centralized level.

\begin{tabular}{|c|c|c|c|c|c|c|c|c|c|c|}
\hline \multirow{3}{*}{ Year } & \multicolumn{10}{|c|}{ Appendix I - Deaths and productive years of life lost to coronary heart disease in the male sex in Brazil, 1979-1998 } \\
\hline & \multicolumn{2}{|c|}{$20-29$} & \multicolumn{2}{|c|}{$30-39$} & \multicolumn{2}{|c|}{$40-49$} & \multicolumn{2}{|c|}{$50-59$} & \multicolumn{2}{|c|}{$20-59$} \\
\hline & Deaths & PYLL & Deaths & $\overline{\text { PYLL }}$ & Deaths & $\overline{\text { PYLL }}$ & Deaths & $\overline{\text { PYLL }}$ & Deaths & PYLL \\
\hline 1979 & 319 & 11,165 & 1,133 & 28,325 & 3,320 & 49,800 & 5,975 & 29,875 & 10,747 & 119,165 \\
\hline 1980 & 302 & 10,570 & 1,159 & 28,975 & 3,465 & 51,975 & 6,445 & 32,225 & 11,371 & 123,745 \\
\hline 1981 & 316 & 11,060 & 1,194 & 29,850 & 3,440 & 51,600 & 6,576 & 32,880 & 11,526 & 125,390 \\
\hline 1982 & 287 & 10,045 & 1,162 & 29,050 & 3,304 & 49,560 & 6,544 & 32,720 & 11,297 & 121,375 \\
\hline 1983 & 356 & 12,460 & 1,314 & 32,850 & 3,619 & 54,285 & 6,943 & 34,715 & 12,232 & 134,310 \\
\hline 1984 & 339 & 11,865 & 1,369 & 34,225 & 3,677 & 55,155 & 7,145 & 35,725 & 12,530 & 136,970 \\
\hline 1985 & 350 & 12,250 & 1,390 & 34,750 & 3,687 & 55,305 & 7,380 & 36,900 & 12,807 & 139,205 \\
\hline 1986 & 360 & 12,600 & 1,558 & 38,950 & 3,860 & 57,900 & 7,410 & 37,050 & 13,188 & 146,500 \\
\hline 1987 & 349 & 12,215 & 1,505 & 37,625 & 3,854 & 57,810 & 7,642 & 38,210 & 13,350 & 145,860 \\
\hline 1988 & 360 & 12,600 & 1,574 & 39,350 & 4,160 & 62,400 & 7,983 & 39,915 & 14,077 & 154,265 \\
\hline 1989 & 360 & 12,600 & 1,645 & 41,125 & 4,111 & 61,665 & 7,609 & 38,045 & 13,725 & 153,435 \\
\hline 1990 & 342 & 11,970 & 1,439 & 35,975 & 3,900 & 58,500 & 7,634 & 38,170 & 13,315 & 144,615 \\
\hline 1991 & 333 & 11,655 & 1,371 & 34,275 & 3,774 & 56,610 & 7,273 & 36,365 & 12,751 & 138,905 \\
\hline 1992 & 264 & 9,240 & 1,461 & 36,525 & 3,882 & 58,230 & 7,205 & 36,025 & 12,812 & 140,020 \\
\hline 1993 & 282 & 9,870 & 1,499 & 37,475 & 3,914 & 58,710 & 7,447 & 37,235 & 13,142 & 143,290 \\
\hline 1994 & 310 & 10,850 & 1,434 & 35,850 & 4,085 & 61,275 & 7,433 & 37,165 & 13,262 & 145,140 \\
\hline 1995 & 285 & 9,975 & 1,421 & 35,525 & 4,136 & 62,040 & 7,590 & 37,950 & 13,432 & 145,490 \\
\hline 1996 & 293 & 10,255 & 1,452 & 36,300 & 4,322 & 64,830 & 7,697 & 38,485 & 13,764 & 149,870 \\
\hline 1997 & 293 & 10,255 & 1,452 & 36,300 & 4,461 & 66,915 & 7,694 & 38,470 & 13,900 & 151,940 \\
\hline 1998 & 298 & 10,430 & 1449 & 36,225 & 4,693 & 70,395 & 8,151 & 40,755 & 14,591 & 157,805 \\
\hline Mean & 319.9 & $11,196.5$ & 1,399 & 35,525 & 3,883 & 58,248 & 7,289 & 36,444 & 12,891 & 140,865 \\
\hline $\mathrm{SD}^{*}$ & 30.1 & $1,053.7$ & 139.4 & $3,486.3$ & 360.9 & $5,413.2$ & 534.3 & $2,671.7$ & 991.3 & $10,939.3$ \\
\hline$\%$ of I or R** & -6.6 & & +27.9 & & +41.4 & & +36.4 & & +35.8 & \\
\hline
\end{tabular}




\begin{tabular}{|c|c|c|c|c|c|c|c|c|c|c|}
\hline \multicolumn{11}{|c|}{ Appendix II - Deaths and productive years of life lost to coronary heart disease in the female sex in Brazil, 1979-1998 } \\
\hline \multirow[b]{2}{*}{ YEAR } & \multicolumn{2}{|c|}{$20-29$} & \multicolumn{2}{|c|}{$30-39$} & \multicolumn{2}{|c|}{$40-49$} & \multicolumn{2}{|c|}{$50-59$} & \multicolumn{2}{|c|}{$20-59$} \\
\hline & Deaths & PYLL & Deaths & PYLL & Deaths & PYLL & Deaths & PYLL & Deaths & PYLL \\
\hline 1979 & 146 & 5,110 & 521 & 13,025 & 1,209 & 18,135 & 2,396 & 11,980 & 4,272 & 48,250 \\
\hline 1980 & 151 & 5,285 & 478 & 11,950 & 1,273 & 19,095 & 2,590 & 12,950 & 4,492 & 49,280 \\
\hline 1981 & 151 & 5,285 & 500 & 12,500 & 1,320 & 19,800 & 2,574 & 12,870 & 4,545 & 50,455 \\
\hline 1982 & 131 & 4,585 & 482 & 12,050 & 1,228 & 18,420 & 2,483 & 12,415 & 4,324 & 47,470 \\
\hline 1983 & 159 & 5,565 & 548 & 13,700 & 1,349 & 20,235 & 2,749 & 13,745 & 4,805 & 53,245 \\
\hline 1984 & 132 & 4,620 & 557 & 13,925 & 1,479 & 22,185 & 2,844 & 14,220 & 5,012 & 54,950 \\
\hline 1985 & 148 & 5,180 & 571 & 14,275 & 1,399 & 20,985 & 3,003 & 15,015 & 5,121 & 55,455 \\
\hline 1986 & 172 & 6,020 & 636 & 15,900 & 1,545 & 23,175 & 3,225 & 16,125 & 5,578 & 61,220 \\
\hline 1987 & 160 & 5,600 & 584 & 14,600 & 1,615 & 24,225 & 3,176 & 15,880 & 5,535 & 60,305 \\
\hline 1988 & 167 & 5,845 & 651 & 16,275 & 1,637 & 24,555 & 3,384 & 16,920 & 5,839 & 63,595 \\
\hline 1989 & 149 & 5,215 & 646 & 16,150 & 1,677 & 25,155 & 3,304 & 16,520 & 5,776 & 63,040 \\
\hline 1990 & 130 & 4,550 & 546 & 13,650 & 1,532 & 22,980 & 3,222 & 16,110 & 5,430 & 57,290 \\
\hline 1991 & 147 & 5,145 & 562 & 14,050 & 1,514 & 22,710 & 3,066 & 15,330 & 5,289 & 57,235 \\
\hline 1992 & 119 & 4,165 & 513 & 12,825 & 1,462 & 21,930 & 3,191 & 15,955 & 5,285 & 54,875 \\
\hline 1993 & 117 & 4,095 & 594 & 14,850 & 1,639 & 24,585 & 3,250 & 16,250 & 5,600 & 59,780 \\
\hline 1994 & 111 & 3,885 & 599 & 14,975 & 1,708 & 25,620 & 3,342 & 16,710 & 5,760 & 61,190 \\
\hline 1995 & 134 & 4,690 & 620 & 15,500 & 1,832 & 27,480 & 3,572 & 17,860 & 6,158 & 65,530 \\
\hline 1996 & 139 & 4,865 & 658 & 16,450 & 1,819 & 27,285 & 3,614 & 18,070 & 6,230 & 66,670 \\
\hline 1997 & 128 & 4,480 & 578 & 14,450 & 1,858 & 27,870 & 3,563 & 17,815 & 6,127 & 64,615 \\
\hline 1998 & 140 & 4,900 & 584 & 14,600 & 2,042 & 30,630 & 3,699 & 18,495 & 6,465 & 68,625 \\
\hline Means & 141 & 4,950 & 576 & 14,388 & 1,569 & 23,540 & 3,136 & 15,581 & 5,423 & 58,559 \\
\hline $\mathrm{SD}^{*}$ & 15.7 & 563.0 & 55.2 & $1,379.8$ & 222.7 & $3,340.3$ & 387.7 & $1,938.7$ & 645.59 & $6,290.6$ \\
\hline$\%$ of I or $\mathrm{R}^{* *}$ & -4.1 & & +12.1 & & +68.9 & & +54.4 & & +51.3 & \\
\hline
\end{tabular}

\section{References}

1. Roemeder JM, McWhinnie JR. Potential years of life lost between ages of 1 and 70: an indicator of premature mortality for health planning. Int J Epidemiol 1977: 6: 143-51.

2. Blane $D$, Drever $F$. Inequality among men in standardized years of potential life lost, 1970-93. Br Med J 1998; 317: 255-60.

3. Barreto ML, Hage E. Tendências recentes das doenças crônicas no Brasil. In: Lessa I. O Adulto Brasileiro e as Doenças da Modernidade. Epidemiologia das Doenças Crônicas Não- Transmissíveis. $1^{a}$ Ed, São Paulo: Hucitec-ABRASCO, 1998: cap.1.

4. Lessa I, Mendonça GAS, Teixeira MTB. Doenças crônicas não-transmissívis no Brasil: dos fatores de risco ao impacto social. Bol Oficina Sanit Panam 1996; 120 : 369-413.

5. Lessa I. Aspectos sociais da mortalidade precoce (15-59 anos) por doenças cerebrovasculares. Arq Neuro-Psiquiat 1990; 48: 296-300.

6. Lessa I. Epidemiologia do tratamento e da adesão ao tratamento da hipertensão arterial e do diabetes mellitus in: Lessa I. O adulto Brasileiro e as Doenças da Modernidade. Epidemiologia das Doenças Crônicas Não-Transmissíveis. $1^{\mathrm{a}}$ Ed. São Paulo: Hucitec-ABRASCO, 1998: cap. 13.

7. Lessa I, Fonseca MJ. Adesão de hipertensos ao tratamento e/ou consulta. Arq Bras Cardiol 1997; 68: 443-9.

8. Busnello RG, Melchior R, Faccin C, et al. Características associadas ao abandono do acompanhamento de pacientes hipertensos atendidos em um ambulatório de referência. Arq Bras Cardiol 2001; 76: 249-354.

9. Lessa I. Years of productive life lost to prematures mortality from cardiovascular diseases. Bull of PAHO 1991; 25: 229-36.

10. Lessa I, Anos produtivos de vida perdidos por mortalidade precoce (20-59 anos) pelo diabetes mellitus. Arq Bras Med 1996; 70: 313-8.

11. Lessa I. Cirrhosis of the liver in Brazil: mortality and productive years of life lost prematurely. Pan Am J Public Health 1997; 125-32.
12. Lolio CA, Lotufo PA, Lira AC, Zanetta DM, MassadE. Tendência da mortalidade por doença isquêmica do coração nas capitais de regiões metropolitanas do Brasil, 1979-1989. Arq Bras Cardiol 1995; 64: 195-9.

13. Duncan BB, Schmidit MI, Polanczyk CA Mengue SS. Altos coeficientes de mortalidade na população adulta brasileira. Uma comparação internacional. Rev Assoc Med Bras 1992; 38: 138-44.

14. Barnett E, Armstrong DL, Casper ML. Evidence of increasing coronary heart disease mortality among black men of lower social class. Ann Epidemiol 1999; 9: 461-71.

15. Alderman MH, Cohen HW, Madhavan S. Myocardial infarction in treated hypertensive patients: the paradox of lower incidence but high mortality in young blacks compared with whites. Circulation 2000; 101: 1109-14.

16. Barnett $\mathrm{E}$, Halverson J. Disparities in premature coronary heart disease mortality by region and urbanicity among black and white adults ages 35-64, 1985-1995. Public Health Rep 2000; 115: 52-5.

17. Blane D, Smith GD, Bartley M. Social class differences in years of potential life lost: trends and principal causes. Br Med J 1990; 301: 429-32.

18. Wigle DT, Mao Y, Semenciw R, McCann C, Davies JW. Premature deaths in Canada: impact, trends and opportunities for prevention. Can Public Health 1990; 81:376-81.

19. Fox P, Gazzaniga J, Karter A, Max W. The economic costs of cardiovascular disease mortality in California, 1991: implications for public health policy. J Public Health Policy 1996; 17: 442-59.

20. National Institute of Health. The Sixth Report of the Joint Nationl Committee on Prevention, Detection, Evaluation, and Treatment 1 of High Blood Pressure. Arch Intern Med 1997; 157: 2413-46.

21. Capeweel S, Beaglehole R, Seddon M, McMurray J. Explanation for the decline in coronary heart disease mortality rates in Auckland, New Zeland, between 19821993. Circulation 2000; 102: 1511-6. 